\title{
Ітераційний метод “динамічної ефективності” при багатомірній задачі лінійного програмування для підвищення ефективності ресурсного забезпечення
}

\author{
Анатолій Невольніченко ${ }^{1}$; ; Руслан Бойко * 2 в; Анатолій Лойшин ${ }^{3}$ с \\ А Незалежний експерт, м. Київ, Україна

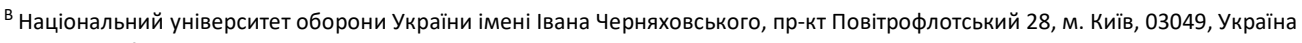 \\ С Головна інспекція Міністерства оборони України, пр-кт Повітрофлотський 6, м. Київ, 03168, Україна
}

Received: September 25, 2021 | Revised: October 4, 2021 | Accepted: October 30, 2021

DOI: $10.33445 /$ sds.2021.11.5.3

\begin{abstract}
Анотація
Типова задача оптимального розподілу ресурсів відома у дослідженні операцій як задача лінійного програмування з багатомірним аргументом, виникає при прийнятті рішень щодо управління "складною ергатичною бойовою системою (БС)" при їі створенні («тендерна» задача) і застосуванні (“транспортна" задача). “Тендерна" задача полягає у пошуку оптимального плану замовлень і постачань різнорідних ресурсів для створення елементів (об'єктів) структури БС, який максимізує ефективність використання бюджетних засобів (видатків). "Транспортна" задача полягає у пошуку оптимального плану замовлень і постачань різнорідних витратних ресурсів для відновлення боєздатності елементів (об'єктів) структури БС, яка підвищує ефективність використання витрат на ресурсне забезпечення. Якщо в тендерній задачі видатки $€$ вартістю ресурсу і вартістю його постачання, то у транспортній задачі витрати $€$ тільки "транспортними" (на постачання). В основу запропонованого методичного підходу пропонується універсальна постановка задач даного класу і універсальний ітераційний метод “динамічної ефективності" їх вирішення, що є розвитком методів теорії оптимальних рішень у воєнній кібернетиці. Головне практичне значення запропонованого підходу полягає в тому, що він дозволить вирішити даного класу задачі при незбалансованості постачання ресурсів.
\end{abstract}

Ключові слова: ефективність, ресурси, замовники, постачальники.

\section{Постановка проблеми}

Задача оптимального розподілу ресурсів відома у дослідженні операцій як задача лінійного програмування 3 багатомірним аргументом яка $€$ поєднанням “тендерної" i “транспортної" задач.

За пошук оптимального варіанту виконання замовлень і постачань різнорідних ресурсів для створення елементів (об'єктів) структури БС відповідає “тендерна" задача. “Транспортна" задача полягає у пошуку оптимального плану замовлень і постачань різнорідних витратних ресурсів для відновлення боєздатності елементів (об'єктів) структури БС, яка максимізує ефективність використання витрат на ресурсне забезпечення. Якщо в тендерній задачі видатки є вартістю ресурсу і вартістю його постачання, то у транспортній задачі витрати $€$ тільки “транспортними" (на постачання).

Існуючі методи постановки і вирішення даного класу задач потребують “регуляризації" задач при незбалансованості за ресурсами, і в цілому непридатні для вирішення задач з багатомірним аргументом і задач 3 додатковими (до ресурсних) обмеженнями, а також для вирішення як

\footnotetext{
${ }^{1}$ д.в.н., с.H.C., e-mail: ailowen35@gmail.com, ORCID: 0000-0002-6247-1970

$2 *$ Corresponding author: к.T.н., с.н.с., провідний науковий співробітник, e-mail: boyko1975@ukr.net, ORCID: 0000-0001-7240-4299

${ }^{3}$ доктор философии, старший инспектор Главной инспекции, e-mail: aloishyn@gmail.com, ORCID: 0000-0003-2769-9336
} 


\begin{tabular}{ll}
\hline “прямих”, так і “обернених” задач за єдиною & удосконаленням процесів ресурсного \\
процедурою. & забезпечення $\epsilon$ достатньо актуальним та \\
Тому дослідження питань пов'язаних із & своєчасним завданням сьогодення.
\end{tabular}

\section{Аналіз останніх досліджень та публікацій}

Питанню вдосконалення існуючої системи ресурсного забезпечення приділяється багато уваги. Нажаль, існуючі методи вирішення прямих і обернених тендерних (транспортних) задач 3 багатомірним аргументом при незбалансованості за ресурсами не дають бажаного результату.

Метод “динамічної ефективності (ДЕ) елементів поточного рішення" доповнює методи лінійного програмування для вирішення даного класу задач, має переваги над “симплексним" методом и методом “потенціалів" щодо відсутності необхідності "регулярізації" задачі при ії незбалансованості за ресурсами, а також щодо можливості вирішення єдиною ітераційною процедурою повної множини “прямих" i "обернених" незбалансованих за ресурсами задач.

\section{Постановка завдання}

Формулювання мети статті. Тому, метою статті $€$ пошук шляхів удосконалення системи ресурсного забезпечення при різнорідних ресурсах і додаткових обмеженнях щодо їх постачання.

\section{Виклад основного матеріалу}

Розглянемо зміст багатомірної задачі даного класу. Завданий наступний робочій набір вихідних даних для задачі.

Постачальники різнорідних ресурсів (найменування) -

$$
P_{i}, i=\overline{1, m} \text {. }
$$

Замовники різнорідних ресурсів (найменування) -

$$
Q_{j}, j=\overline{1, n} .
$$

Види різнорідних ресурсів (найменування) -

$$
R_{k}, k=\overline{1, z} \text {. }
$$

Запаси постачальників (за видами ресурсів) - матриця

$$
A_{m z}=\left\|a_{i k}\right\|_{m \times z} .
$$

Потреби замовників (за видами ресурсів) матриця

$$
B_{n z}=\left\|b_{j k}\right\|_{n \times z} \text {. }
$$

Загальна “комунікація" замовників і постачальників - матриця

$$
V_{m n}=\left\|v_{i j}=(1 ; 0)\right\|_{m \times n^{\prime}}
$$

де елемент матриці приймає наступні значення $-$

$v_{i j}=1$, якщо існує "комунікація" між $i-м$ постачальником та ј-м замовником;

$v_{i j}=0$ у протилежному випадку.

Елемент матриці може приймати значення відносного “пріоритету" щодо комунікації

$$
V_{m n}=\left\|\left(0 \leq v_{i j} \leq 1\right)\right\|_{m \times n} .
$$

Загальна “комунікація" замовників і постачальників за видами ресурсів, як додаткова умова - матроїд

$$
V_{m n z}=\left\|v_{i j k}=(1 ; 0)\right\|_{m \times n \times z^{\prime}}
$$

де елемент матроїда приймає наступні значення -

$v_{i j k}=1$, якщо існує "комунікація" між $і$-м постачальником та $j-m$ замовником за ресурсом $k$-го виду;

$v_{i j k}=0$ у протилежному випадку.

Елементи матроїда можуть приймати значення відносних “пріоритетів" щодо "комунікації" між постачальниками і замовниками за видами ресурсів -

$$
\|\|\left(0 \leq v_{i j k} \leq 1\right) \|\left.\right|_{m \times n \times z}
$$


Питомі витрати на замовлення (постачання) ресурсів за видами - матроїд

$$
C_{m n z}=\left|\left\|c_{i j k}\right\|\right|_{m \times n \times z^{\prime}}
$$

де $c_{i j k}-$ вартість постачання одиниці ресурсу $k$ го виду i-м постачальником j-му замовнику.

Загальні запаси постачальників (об'єми за видами ресурсів) - вектор

$$
A_{k}=\sum_{i=1}^{m} a_{i k}, \quad k=\overline{1, z} .
$$

Загальні потреби замовників (за видами ресурсів) - вектор

$$
B_{k}=\sum_{i=1}^{m} b_{j k}, \quad k=\overline{1, z}
$$

Можливі (при незбалансованості задачі за ресурсами $\left.\quad A_{k} \neq B_{k}, k=\overline{1, z}\right) \quad$ об'єми постачання (за видами ресурсів), очевидно, дорівнюватимуть -

$$
W_{k}=\min \left(A_{k}, B_{k}\right), k=\overline{1, z} .
$$

План замовлень і постачань - багатомірний (3-мірний $m, n, z)$ "матроїд" загальної розмірності $m \times n \times z$ компонент -

$$
X_{m n z}=\left|\left\|x_{i j k}\right\|\right|_{m \times n \times z^{\prime}}
$$

"елементом" якого $x_{i j k} \in$ значення кількості (розрахункових одиниць) ресурсу $k$-го виду, що постачає $i$-й постачальник j-му замовнику. При даному плані замовлень-постачань його "вартість", вочевидь, складе -

$$
C S(X)=\sum_{i=1}^{m} \sum_{j=1}^{n} \sum_{k=1}^{Z}\left(c_{i j k} x_{i j k}\right) .
$$

При цьому елементи матроїда "комунікації" $\left|\left\|\left(0 \leq v_{i j k} \leq 1\right)\right\|\right|_{m \times n \times z} \quad$ мають сенс "пріоритетів" при обчисленні саме "динамічної ефективності" поточних (для кожної ітерації процесу вирішення задачі) компонент рішення (14) -

$$
E_{m n z}(X)=\left|\left\|e_{i j k}=v_{i j k}\left(w_{i j k} / c_{i j k}\right)\right\|\right|_{m \times n \times z^{\prime}}
$$

де $w_{i j k}$ - можливий умовний (для поточної ітерації) об'єм постачань $k$-го ресурсу $i-m$ постачальником j-му замовнику.

Розглянемо геометричну інтерпретацію (в ізометричній проекції) робочого набору вихідних даних і рішення задачі (рис.1).

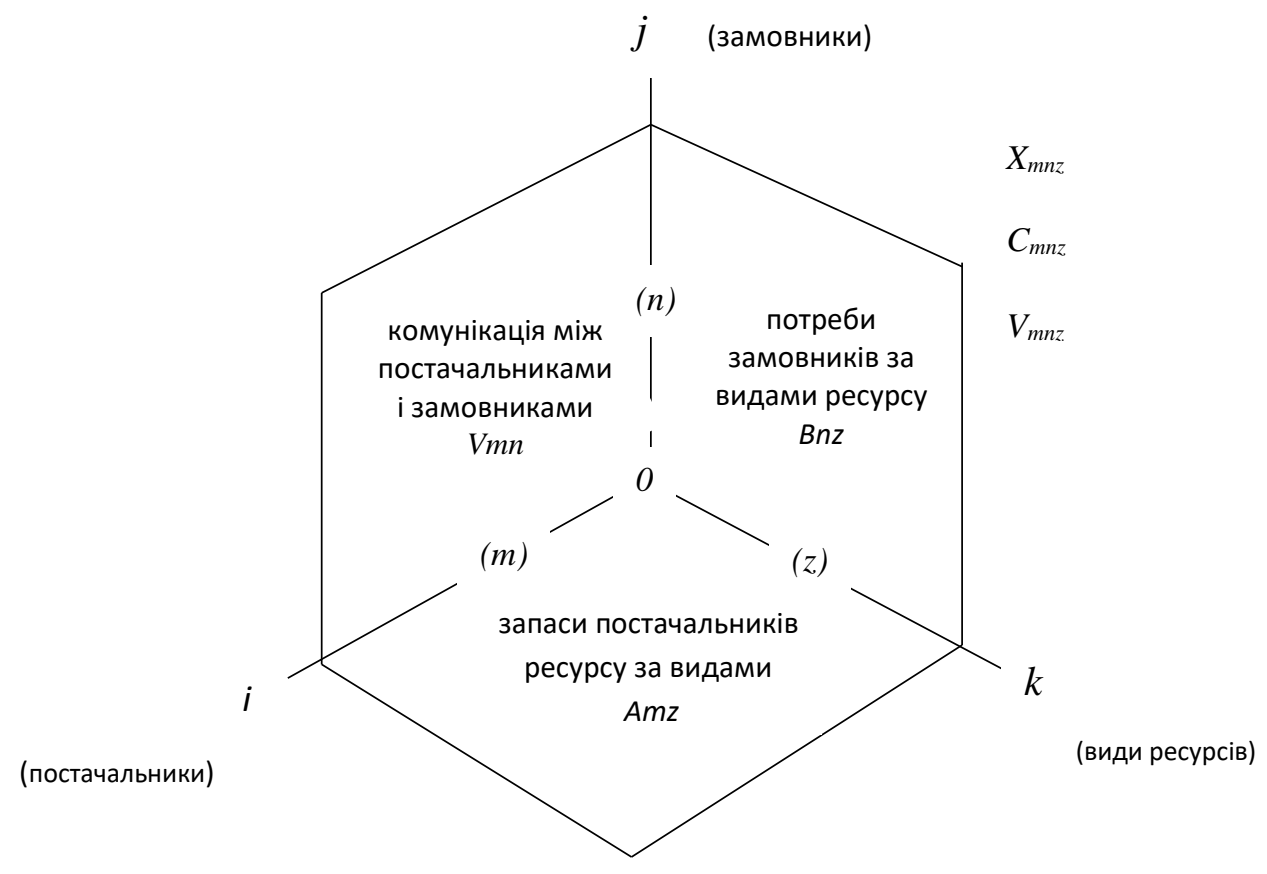

Рисунок 1 - Опорні грані (матриці обмежень) матроїдів рішення $X_{m n z}$ питомих витрат $C_{m n z}$ і пріоритетів $V_{m n z}$

Для даної задачі матроїди $X_{m n z}, C_{m n z}, V_{m n z}$ геометрично завдаються "об'ємом" прямокутного шестигранника у трьохмірному просторі з координатними осями $i, j$, k. Компоненти кожного матроїда $€$ його елементарними "об'ємами".

Кожна матриця вихідних даних-обмежень $\epsilon$ відповідна «несуча поверхня»-грань, що 
“обслуговує” відповідними вихідними даними множину елементів матроїдарішення $X_{\text {mпz. }}$

Зміст елементів “опорних" граней данихобмежень для матроїда “плану замовленьпостачань" наступний:

горизонтальна площина-грань (iok) матриця "запаси постачальників ресурсів за видами";

вертикальна площина-грань $\left(i_{0 j}\right)$ - умови “комунікації" між замовниками і постачальниками (з можливою додатковою “деталізацією” за видами ресурсів).

фронтальна площина-грань (jok) - матриця «потреби замовників ресурсів за видами».

Кожна “матриця-шар” матроїда $X_{m n z}$, що паралельна горизонтальній грані, $€$ частинним планом постачань для $j$-го замовника (по постачальниках і об'ємах ресурсів за видами).

Кожна “матриця-шар" матроїда, що паралельна вертикальній грані, $€$ частинним планом замовлень-постачань об'ємів ресурсу кожного $k$-го виду.

Кожна “матриця-шар" матроїда, що паралельна фронтальній грані, $є$ частинним планом замовлень для i-го постачальника (по замовниках і об'ємах ресурсів за видами).

Геометрична інтерпретація задачі дозволяє, таким чином, коректно визначити обмеження, що накладаються на множину припустимих рішень $\{X\}$ задачі. Так, при певному плані $X_{m n z}(14)$ :

кількість ресурсу (за видами), що буде “поставлений" кожним постачальником, не повинна перевищувати його запаси -

$$
\begin{aligned}
& \left\|\sum_{j=1}^{n} x_{i j k} \leq a_{i k}\right\|_{m \times z}
\end{aligned}
$$

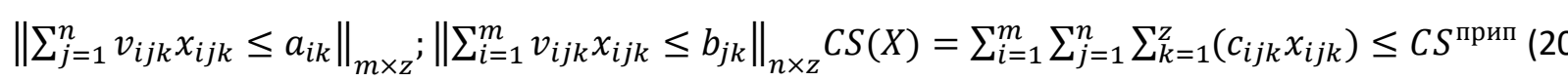

кількість ресурсу (за видами), що буде "одержаний" кожним замовником, не повинна перевищувати його потреби -

$$
\left\|\sum_{i=1}^{m} x_{i j k} \leq b_{j k}\right\|_{n \times z} ;
$$

кількість ресурсу за видами, що може бути поставлена, повинна бути не менша мінімуму із загальних запасів постачальників або потреб замовників -

$$
\begin{aligned}
& W_{k}(X)=\sum_{i=1}^{m} \sum_{j=1}^{n} x_{i j k} \geq \\
& \min \left(A_{k}, B_{k}\right), \quad k=\overline{1, z} .
\end{aligned}
$$

Саме обмеження (17)-(19) і умова “комунікації за пріоритетами" відрізняють дану постановку задачі від класичної.

Виникає дві наступні інтерпретації задачі оптимального планування "замовленьпостачань" різнорідних ресурсів (змістова постановка):

пряма задача - максимальний об'єм постачань (за видами ресурсів) при обмеженнях на витрати (тендерна задача в інтересах замовників);

обернена задача - потрібний (або можливий) об'єм постачань (за видами ресурсів) при мінімумі витрат (транспортна задача в інтересах постачальників).

Оскільки обидві інтерпретації максимізують співвідношення "ефекту" i "витрат", то, тим самим, максимізують ефективність "складної системи" в процесі застосування.

Формальна постановка прямої задачі: критерій придатності рішень $-\forall X, X=$

$$
\|\| x_{i j k} \|\left.\right|_{m \times n \times z} \subset\{X\}:
$$

критерій оптимальності рішення -

$$
\exists X^{o}, X^{o}=\left|\left\|x_{i j k}^{o}\right\|\right|_{m \times n \times z} \subset\{X\}: W_{k}\left(X^{o}\right)=\sum_{i=1}^{m} \sum_{j=1}^{n} x_{i j k}^{o}=\max _{\{X\}} W_{k}(X), k=\overline{1, z} .
$$

Оскільки різнорідні ресурси неприпустимо просто підсумовувати, то тут максимізуються можливі об'єми постачань за кожним видом ресурсів. 
Дана задача $є$ другорядною, оскільки для обмежених (наявних) витрат максимізується ефект (об'єм постачань ресурсів), який в загальному випадку не співпадає з потрібнім для "успіху" операції.

$$
\left\|\sum_{j=1}^{n} v_{i j k} x_{i j k} \leq a_{i k}\right\|_{m \times z} ;\left\|\sum_{i=1}^{m} v_{i j k} x_{i j k} \leq b_{j k}\right\|_{n \times z} ; \sum_{i=1}^{m} \sum_{j=1}^{n} x_{i j k} \geq W_{k}, \quad k=\overline{1, z}
$$

критерій оптимальності рішення -

$$
\exists X^{o}, X^{o}=\left|\left\|x_{i j k}^{o}\right\|\right|_{m \times n \times z} \subset\{X\}: C S\left(X^{o}\right)=\sum_{i=1}^{m} \sum_{j=1}^{n} \sum_{k=1}^{Z}\left(c_{i j k} x_{i j k}^{o}\right)=\min _{\{X\}} C S(X) .
$$

Дана задача $є$ основною, оскільки для потрібного (для "успіху" операції) ефекту мінімізуються витрати на його досягнення.

Вирішення даних задач класичними методами лінійного програмування неможливе через те, що аргумент цільової функції і функцій-обмежень $€$ багатомірним (саме трьохмірним матроїдом, на відзнаку від одномірного вектору чи двомірної матриці), а також наявності додаткового “цільового” показника “можливий об'єм постачань", бінарних умов щодо комунікації “постачальник-замовник” і “пріоритетів постачань" за видами ресурсів. Тому для вирішення даних задач науковцями розроблений спеціальний метод лінійного програмування - ітераційний метод “динамічної ефективності елементів поточного рішення", який дозволяє без попередньої “регуляризації” (перехід до векторної форми поточного рішення 3 поверненням до матричної форми оптимального рішення, введення фіктивних постачальників і замовників) вирішувати незбалансовані по запасах і потребах ресурсів прямі й обернені багатомірні задачі. Метод дозволяє вирішувати "транспортні" й "тендерні" задачі, як "типові" задачі лінійного програмування (лП) 3 багатомірним дискретним (в тому числі і цілочисловим) аргументом [1-4].

Динамічною ефективністю $e_{i j k}$ поточного рішення (на певній ітерації) для кожної компоненти (елемента) $\boldsymbol{x}_{i j k}$ матроїда $X_{m n z}$ вважається зважене за "пріоритетами" $v_{i j k}$ значення співвідношення можливого “умовного об'єму" $w_{i j k}$ постачання ресурсу $k$ го виду i-м постачальником j-му замовнику i вартості постачання одиниці даного ресурсу сіjk; при цьому виникає матроїд "динамічної ефективності" поточного рішення -

$$
E\left(X_{m n z}\right)=||\left|e_{i j k}=v_{i j k}\left(w_{i j k} / c_{i j k}\right) \|\right|_{m \times n \times z^{\prime}}
$$

де "умовні об'єми" $є$ також матроїдом -

$$
W_{m n z}=\left|\left\|w_{i j k}=\min \left(a_{i k}, b_{j k}\right)\right\|\right|_{m \times n \times z}
$$

На кожній ітерації процесу вирішення задачі визначається одиниця ресурсу 3 “глобально" максимальною (на матроїді $E$ ) динамічною ефективністю і безумовно "додається" відповідній компоненті плану замовлень-постачань. Після цього корегується масив поточних запасів постачальників і масив поточних потреб замовників, в результаті чого змінюються (саме зменшуються) відповідні масиви умовних об'ємів постачань і динамічні ефективності одиниць ресурсів, накопичуються поточні об'єми витрат і ефекту перед наступною ітерацією розподілу. Умовою закінчення ітераційної процедури $\epsilon$ досягнення припустимого рівня витрат на постачання для “прямої" задачі або досягнення потрібного рівня ефекту (об'єму постачань) для “оберненої" задачі. Значення елементів матроїду $X_{m n z}$ на останній ітерації визнаються оптимальними, а значення ефекту і витрат - екстремальними. Для оберненої задачі кількість ітерацій дорівнюватиме, очевидно, сумі можливих об'ємів постачань ресурсів усіх видів.

Таким чином, метод “ДЕ елементів поточного рішення" реалізує процедуру "градієнтного пошуку" оптимуму i тому забезпечує сувору збіжність процедури. Крім того, даний метод дозволяє єдиною 
процедурою вирішувати повну множину “вкладених" тендерних (транспортних) задач оптимального розподілу ресурсів.

Алгоритм методу ДЕ для вирішення задачі на ЕОМ полягає у наступному.

\section{Початкові присвоювання:}

ввід значень $m, n, z$;

оголошення і заповнення вихідними даними масивів $P_{m}, Q_{n}, A_{m z}, B_{n z}, C_{m n z}, V_{m n z}$;

ввід значень припустимих витрат CS для “прямої" задачі, присвоювання поточному значенню витрат $c s:=0$;

обчислення потрібного значення ефекту (можливих об'ємів постачань за кожним видом ресурсів) згідно з (23), для “оберненої" задачі - WS, присвоювання поточному значенню ефекту $w s:=0$;

$$
x_{r s t}:=x_{r s t}+1 ; \quad a_{r t}:=a_{r t}-1 ; \quad b_{s t}:=b_{s t}-1 ; \quad c s:=c s+c_{r s t} ; \quad w s:=w s+w_{r s t} .
$$

Крок 3. Перевірка умови закінчення ітераційної процедури:

для прямої задачі - чи (cs $\geq C S)$ ? (29)

для оберненої задачі - чи (ws $\geq W S)$ ? присвоювання значень елементам матроїда $X_{m n z}=\left|\left\|x_{i j k}:=0\right\|\right|_{m \times n \times z} ;$

обчислення значень елементів матроїда $W_{m n z}=\left|\left\|w_{i j k}:=\min \left(a_{i k}, b_{j k}\right)\right\|\right|_{m \times n \times z} ;$ обчислення значень елементів матроїда $\left.E_{m n z}=\mid \| e_{i j k}:=v_{i j k} w_{i j k} / c_{i j k}\right) \|\left.\right|_{m \times n \times z} ;$ номер поточної ітерації $I:=0$.

Ітераційна процедура (I-та ітерація)

Крок 1. Присвоювання l:=l+1.

Крок 2. Пошук на матроїді $E_{m n z}$ глобально максимального елементу

$$
e_{r s t}=\max _{i j k}\left|\left\|e_{i j k}\right\|\right|_{m \times n \times z} ;
$$

присвоювання:

$$
w_{r j t}:=\max \left(a_{r t}, b_{j t}\right), j=\overline{1, n} ; \quad w_{i s t}:=\max \left(a_{i t}, b_{s t}\right), \quad i=\overline{1, m} \text {. }
$$

Крок 5. Перерахунок елементів матриці $E_{r s}$ (по $t$-му виду ресурсу) матроїда $E_{m n z}$ динамічних ефективностей по формулі (25) -

$$
e_{r j t}:=v_{r j t} w_{r j t} / c_{r j t}, j=\overline{1, n} ; \quad e_{i s t}:=v_{i s t} w_{i s t} / c_{i s t}, i=\overline{1, m} .
$$

Перехід до наступної ітерації.

\section{Рішення задачі:}

1. Оптимальний план замовлень і постачань ресурсів - поточний план останньої I-ої ітерації -

$$
X_{m n z}^{(l)}=X_{m n z}^{o}=\left|\left\|x_{i j k}^{o}\right\|\right|_{m \times n \times z}
$$

2. Вартість плану (витрати на постачання) поточне значення витрат останньої l-ої ітерації -

$$
C S^{(l)}=C S\left(X_{i j k}^{o}\right)=\sum_{i=1}^{m} \sum_{j=1}^{n} \sum_{k=1}^{Z}\left(c_{i j k} x_{i j k}^{o}\right) .
$$

3. Статок запасу постачальників (за видами ресурсів) після останньої І-ої ітерації -

$$
A_{m z}^{(l)}=\left\|a_{i k}\right\|_{m \times z} .
$$

4. Нестача у замовників (за видами ресурсів) після останньої І-ої ітерації -

$$
B_{n z}^{(l)}=\left\|b_{j k}\right\|_{n \times z} .
$$

5. Кількість ітерації - I.

Далі оптимальний план-матроїд деталізується у вигляді планів-матриць "замовлень" для $m$ постачальників і планівматриць "постачань" для $n$ замовників.

Плани "замовлень" $є m$ "матрицями-шарами" оптимального рішення-матроїда, паралельними фронтальній площині простору рішень (рис. 1), тобто

$$
X_{i}^{o}=\left\|x_{i j k}^{o}\right\|_{n \times z^{\prime}} \quad i=\overline{1, m} .
$$

Завдання плану “замовлень" для кожного i-го постачальника має наступну форму: 


\begin{tabular}{|c|c|c|c|c|c|}
\hline$P_{i}, \quad i=\overline{1, m}$ & ресурс 1 виду & $\ldots$ & ресурс $k$ виду & $\ldots$ & ресурс z виду \\
\hline замовник $Q_{1}$ & $x_{i 11} / c_{i 11}$ & $\ldots$ & $x_{i 1 k} / c_{i 1 k}$ & $\ldots$ & $x_{i 1 z} / c_{i 1 z}$ \\
\hline$\ldots$ & $\ldots$ & $\ldots$ & $\ldots$ & $\ldots$ & $\ldots$ \\
\hline замовник $Q_{j}$ & $x_{i j 1} / c_{i j 1}$ & $\ldots$ & $x_{i j k} / c_{i j k}$ & $\ldots$ & $x_{i j z} / c_{i j z}$ \\
\hline$\ldots$ & $\ldots$ & $\ldots$ & $\ldots$ & $\ldots$ & $\ldots$ \\
\hline замовник $Q_{n}$ & $x_{i n 1} / c_{i n 1}$ & $\ldots$ & $x_{i n k} / c_{i n k}$ & $\ldots$ & $x_{i n z} / c_{i n z}$ \\
\hline
\end{tabular}

Плани “постачань" $€ n$ "матрицямишарами" оптимального рішення-матроїда, паралельними горизонтальній площині простору рішень (рис. 1), тобто

$$
X_{j}^{o}=\left\|x_{i j k}^{o}\right\|_{m \times z^{\prime}}, j=\overline{1, n} .
$$

Завдання плану «постачань» для кожного j-го замовника має наступну форму:

\begin{tabular}{|c|c|c|c|c|c|}
\hline$Q_{j}, \quad j=\overline{1, n}$ & ресурс 1 виду & $\ldots$ & ресурс $k$ виду & $\ldots$ & ресурс z виду \\
\hline постачальник $P_{1}$ & $x_{1 j 1} / c_{1 j 1}$ & $\ldots$ & $x_{1 j k} / c_{1 j k}$ & $\ldots$ & $x_{1 j z} / c_{1 j z}$ \\
\hline$\ldots$ & $\ldots$ & $\ldots$ & $\ldots$ & $\ldots$ & $\ldots$ \\
\hline постачальник $P_{i}$ & $x_{i j 1} / c_{i j 1}$ & $\ldots$ & $x_{i j k} / c_{i j k}$ & $\ldots$ & $x_{i j z} / c_{i j z}$ \\
\hline$\ldots$ & $\ldots$ & $\ldots$ & $\ldots$ & $\ldots$ & $\ldots$ \\
\hline постачальник $P_{m}$ & $x_{m j 1} / c_{i n 1}$ & $\ldots$ & $x_{m j k} / c_{m j k}$ & $\ldots$ & $x_{m j z} / c_{m j z}$ \\
\hline
\end{tabular}

\section{Висновки}

Метод “динамічної ефективності елементів поточного рішення" доповнює методи лінійного програмування для вирішення прямих і обернених тендерних (транспортних) задач 3 багатомірним аргументом, має переваги над “симплексним" методом и методом “потенціалів» щодо відсутності необхідності “регулярізації" задачі при ії незбалансованості за ресурсами, а також щодо можливості вирішення єдиною ітераційною процедурою повної множини “прямих" i "обернених" незбалансованих за ресурсами задач при різнорідних ресурсах i додаткових обмеженнях щодо їх постачання.

Наданий алгоритм ітераційного методу "динамічної ефективності" налагоджений, перевірений на детермінованість, результативність і масовість і може бути реалізований у спеціальному математичному програмному забезпеченні комп'ютерних засобів автоматизації управління “складними" системами логістики.

\section{Список використаних джерел}

1. Педченко Г. М., Шарий В. І., Невольніченко А. I. Воєнно-наукове забезпечення операцій військ (сил): Монографія. Військовий інститут Національного університету імені Тараса Шевченка, 2010.

2. Коршунов Ю. М. Математические основы кибернетики. «Высшая школа», Москва,
1980.

3. Зайченко Ю. П. Исследование операций. «Вища школа». Киев, 1975.

4. Ткач І. М., Новіков Е. Б. Методи економічних досліджень : навч. посіб. -К. : НУоу ім. Івана Черняховського, 2015. 184 c. ISBN 978-617-7187-00-3 


\title{
Итерационный метод динамической эффективности при многомерной задаче линейного программирования для повышения эффективности ресурсного обеспечения
}

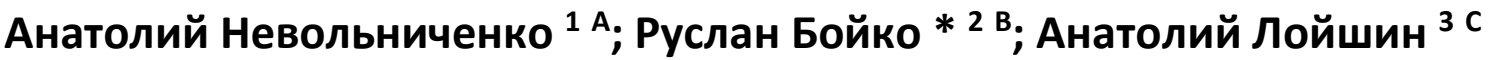 \\ ${ }^{1}$ к.т.H., c.H.C., e-mail: ailowen35@gmail.com, ORCID 0000-0002-6247-1970 \\ * Corresponding author: ${ }^{2}$ к.т.н, с.н.с., ведущий научный сотрудник, e-mail: boyko1975@ukr.net, ORCID 0000-0001-7240-4299 \\ ${ }^{3}$ доктор философии, старший инспектор Главной инспекции, e-mail: aloishyn@gmail.com, ORCID 0000-0003-2769-9336 \\ А Независимый эксперт, г. Киев, Украина

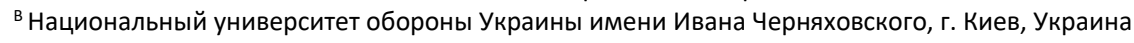 \\ с Главная инспекция Министерства обороны Украины, г. Киев, Украина
}

\begin{abstract}
Аннотация
Типичная задача оптимального распределения ресурсов известна в исследовании операций как задача линейного программирования с многомерным аргументом, которая возникает при принятии решений по управлению “сложной эргодической боевой системой (БС)" при ее создании (“тендерная" задача) и применении (“транспортная" задача). "Тендерная" задача заключается в поиске оптимального плана заказов и поставок разнородных ресурсов для создания элементов (объектов) структуры БС, которая максимизирует эффективность использования бюджетных средств (расходов). "Транспортная" задача заключается в поиске оптимального плана заказов и поставок разнородных расходных ресурсов для восстановления боеспособности элементов (объектов) структуры БС, которая повышает эффективность использования затрат на ресурсное обеспечение. Если в тендерной задаче расходы учитывают стоимость ресурсов и стоимость их доставки, то в транспортной задаче расходы являются только "транспортными" (на доставку).

В основу предложенного методического подхода предлагается универсальная постановка задач данного класса и универсальный итерационный метод "динамической эффективности" их решения, что является развитием методов теории оптимальных решений в военной кибернетике. Главное практическое значение предложенного подхода заключается в том, что он позволит решить данного класса задачи при несбалансированности поставки ресурсов.
\end{abstract}

Ключевые слова: эффективность, ресурсы, заказчики, поставщики.

\section{Iterative method of dynamic efficiency in a multidimensional linear programming problem to increase the efficiency of resource support}

\footnotetext{
Anatoly Nevolnichenko ${ }^{1}$ A; Ruslan Boiko * 2 B; Anatolii Loishyn 3 C

${ }^{1}$ Candidate of Technical Sciences, Senior Research Fellow, e-mail: ailowen35@gmail.com, ORCID: 0000-0002-6247-1970

* Corresponding author: ${ }^{2}$ Candidate of Technical Sciences Senior Research, Leading Researcher, e-mail: boyko1975@ukr.net, ORCID: 0000-0001-7240-4299 ${ }^{3} \mathrm{PhD}$, senior inspector, e-mail: aloishyn@gmail.com, ORCID: 0000-0003-2769-9336

A Independent expert, Kyiv, Ukraine

B The National Defence University of Ukraine named after Ivan Cherniakhovskyi, Kyiv, Ukraine

${ }^{\mathrm{C}}$ General Inspectrateof the Ministryof Defense of Ukraine, Kyiv, Ukraine
}

\begin{abstract}
A typical problem of optimal resource allocation is known in operations research as a linear programming problem with a multidimensional argument, which arises when making decisions to control a "complex ergatic combat system (CS)" during its creation ("tender" problem) and application ("transport" problem). The "tender" task is to find the optimal plan for orders and
\end{abstract}


supplies of heterogeneous resources to create elements (objects) of the CS structure, which maximizes the efficiency of using budget funds (expenses). The "transport" task is to find the optimal plan for orders and supplies of dissimilar consumable resources to restore the combat capability of the elements (objects) of the CS structure, which increases the efficiency of using the costs of resource support. If in the tender task the costs take into account the cost of resources and the cost of their delivery, then in the transport task the costs are only "transport" (for delivery).

The proposed methodological approach is based on a universal formulation of problems of this class and a universal iterative method of "dynamic efficiency" of their solution, which is the development of methods of the theory of optimal solutions in military cybernetics. The main practical value of the proposed approach lies in the fact that it will allow solving this class of problems with an imbalance in the supply of resources.

Keywords: efficiency, resource, customers, suppliers.

\section{References}

1. Pedchenko G. M., Shariy V. I., Nevolnichenko A.I. Military-science safety of operations of vijsk (forces). Monograph. Viskovy Institute of the National University for the Name of Taras Shevchenko, 2010.

2. Korshunov Yu. M. Mathematical foundations of cybernetics. "Higher School", Moscow,
1980.

3. Zaychenko Yu.P. Operations research. "High School". Kiev, 1975.

4. Tkach I. M., Novikov E. B. Metody ekonomichnykh doslidzhen: navch. way. Kyiv : NUOU them. Ivan Chernyakhovsky, 2015. 184 p. ISBN 978-617-7187-00-3 